\title{
Concept Attribution in Nonhuman Animals: Theoretical and Methodological Problems in Ascribing Complex Mental Processes
}

\section{Citation}

Allen, Colin, and Marc David Hauser. 1991. Concept attribution in nonhuman animals:

Theoretical and methodological problems in ascribing complex mental processes. Philosophy of Science 58(2): 221-240.

\section{Published Version}

doi:10.1086/289613

\section{Permanent link}

http://nrs.harvard.edu/urn-3:HUL.InstRepos:3512194

\section{Terms of Use}

This article was downloaded from Harvard University's DASH repository, and is made available under the terms and conditions applicable to Other Posted Material, as set forth at http:// nrs.harvard.edu/urn-3:HUL.InstRepos:dash.current.terms-of-use\#LAA

\section{Share Your Story}

The Harvard community has made this article openly available.

Please share how this access benefits you. Submit a story.

\section{Accessibility}




\title{
CONCEPT ATTRIBUTION IN NONHUMAN ANIMALS: THEORETICAL AND METHODOLOGICAL PROBLEMS IN ASCRIBING COMPLEX MENTAL PROCESSES*
}

\author{
COLIN ALLEN† \\ Department of Philosophy \\ Texas A\&M University \\ MARC D. HAUSER \\ Department of Zoology \\ University of California, Davis
}

\begin{abstract}
The demise of behaviorism has made ethologists more willing to ascribe mental states to animals. However, a methodology that can avoid the charge of excessive anthropomorphism is needed. We describe a series of experiments that could help determine whether the behavior of nonhuman animals towards dead conspecifics is concept mediated. These experiments form the basis of a general point. The behavior of some animals is clearly guided by complex mental processes. The techniques developed by comparative psychologists and behavioral ecologists are able to provide us with the tools to critically evaluate hypotheses concerning the continuity between human minds and animal minds.
\end{abstract}

1. Introduction. Recent willingness to use mentalistic vocabulary to describe animal behavior has resulted from a decline in the popularity of the behaviorist approach to psychology introduced by Watson and championed by Skinner. It has not gone unnoticed that the current problems associated with the use of mentalistic vocabulary to describe animal behavior are similar to those that were faced by comparative psychologists of the nineteenth and early twentieth centuries (see Burghardt 1985 for a comparison of the problems). Then, as now, critics of mentalistic vocabulary in science have suggested that it is overly anthropomorphic and cannot be applied in a testable manner. Behaviorism was a reaction to the often unbridled anthropomorphism of the comparative psychologists. As Burghardt points out, if modern cognitive ethology is to successfully incorporate mentalistic descriptions, it is in need of a methodology that can avoid the charge of excessive anthropomorphism.

In this paper we explore the use of mentalistic terms by cognitive ethol-

*Received July 1988; revised May 1989.

†We wish to thank Tyler Burge, Philip Clark, Lisa Hauser, Alan Nelson, anonymous reviewers for this journal, and, especially, Georges Rey and Keith Donnellan for criticism of earlier drafts of this paper. 
ogists to describe animal behavior. As an example of a mentalistic term, we consider the notion of concept. We consider different aspects of behavior that are associated with human concepts, and address the question of whether it might be appropriate to say that nonhuman animals have concepts. Although, in recent times, philosophers have discussed concepts rather less than they have discussed other cognitive entities such as beliefs, we have chosen to look at concepts because of the somewhat more frequent use of this term by cognitive scientists. This paper is not intended as a review of the literature on categorization by animals (see Harnad 1987 for a series of papers that describe recent research). Neither is it intended as a review of philosophical literature on concepts. Instead, we intend to raise some methodological issues that attend attempts to attribute concepts to animals. In the latter part of the paper, we specifically focus on animal behavior with respect to death and describe a series of experiments that would allow comparison between animal responses to death and concept-mediated human behavior in response to death. These experiments will be posed as thought experiments, enabling us to focus on the particular methodological problems that are associated with such tests. Our analysis of concepts in nonhuman animals is intended to provide ethologists with a level of description of animal cognition that is useful to them in the design of experiments. Philosophers should be interested in the mental abilities of animals since the issues that arise provide a testing ground for philosophical theories of mind. ${ }^{1}$

Griffin (1981) has been foremost in challenging cognitive ethologists to pay more attention to the mental states of animals, especially animal awareness. We have chosen to phrase our discussion in terms of mental states rather than the less innocuous "cognitive processes" since the former are often taken to imply the attribution of properties to animals that are closer to those Griffin challenges ethologists to investigate.

Although biologists have become increasingly more willing to use terms that suggest complex mental states, the use of such terms is sometimes not intended to be taken literally. Terms such as strategy, deceit, cheating, and rape have been deliberately introduced into behavioral ecology (Krebs and Davies 1984) with explicit disavowals of the necessity to invoke any mental states underlying the behaviors described by these terms. As an example of this, Munn (1986) describes a case of "deceitful" alarm calls in mixed species flocks of birds where "deceit" is given a nonmentalistic interpretation. For most philosophers, the question naturally arises

\footnotetext{
${ }^{1}$ In this paper, we cannot hope to take on Wittgensteinean worries about internal representations. One path for cognitive science is to proceed on the assumption that representations guide behavior, and to set itself the task of finding the grammar of those representations (e.g., a la Fodor 1981). It is the task of applying this strategy to animals with which we are concerned in this paper.
} 
whether it is appropriate to call this behavior "deceit" at all since many philosophical analyses of deceit (e.g., ones based on a Gricean account of communication) would require the attribution of complex intentions that the birds almost certainly do not have. Nonetheless, this metaphorical use of terms such as "deceit" is an accepted part of behavioral ecology which must be understood on its own terms.

Other researchers in both behavioral ecology and experimental psychology have intended their use of mentalistic vocabulary much less metaphorically. This is particularly true of those whose research has focused on cognition in nonhuman primates. The apparent sophistication of primates in comparison to most other animals makes them prime candidates for investigation of mental properties. Hinde (1982) remarks that the dangers of anthropomorphism have been much overemphasized and that analysis of primate behavior seems to require use of some mentalistic terms. Behavioral ecologists interested in the link between evolutionary theory and complex mental processes (e.g., Bachmann and Kummer 1980, Kummer 1982, Cheney and Seyfarth 1985) have shown themselves willing to use terms such as "knowledge" and "meaning" to describe the primates they study. It is our view, to be explained below, that mentalistic terminology gives ethologists a mode of description of animals that enables them to explain behavior within an evolutionary framework.

Experimental psychologists cum comparative psychologists have also helped themselves to the use of mentalistic terms. Premack's (1986) elegant experiments on causal inference in chimpanzees illustrate this approach. Although mentalistic terms have most commonly been used for nonhuman primates, behavioral descriptions of other organisms have also drawn upon mentalistic vocabulary (e.g., Gould and Gould 1982). On the basis of Skinnerian experiments, Herrnstein et al. (1976) have implied that pigeons have concepts. Herrnstein's experiments will be discussed in some detail below.

Despite this use of mentalistic terms, most behavioral ecologists, cognitive ethologists and comparative psychologists have not explicitly discussed the theoretical role played by such terms (for exceptions see contributions in Griffin 1982, and Harré and Reynolds 1984). Some philosophers have suggested that mentalistic vocabulary or moderate anthropomorphism might play a heuristic role in hypothesis generation (Dennett 1983, and Asquith 1984) and this view has been endorsed by some researchers of animal behavior (e.g., Burghardt 1985). However, one implication behind some of these suggestions appears to be that mentalistic vocabulary does not directly correspond to any underlying reality. Dennett, for instance, claims that mentalistic terms ultimately will not play any role in scientific description of organisms, eventually being eliminated by descriptions at some other level such as neurophysiology 
(Dennett 1969, 1983). In contrast, Griffin's proposal for the scientific exploration of animal awareness apparently presupposes that the mental states of animals are real phenomena in need of scientific explanation. This seems to us to be a more reasonable attitude towards mental states in animals than the eliminationist position implied by the view that talk of mental states is merely heuristic. Although it is our view that mental attributions are necessary for the adequate explanation of the behavior of some animals, our aim in this paper is not to provide arguments for this claim. Rather, we are concerned with discussing the kinds of experiments that might make mental attributions plausible.

In order to explicate the proper use of mentalistic terms in ethological explanations of nonhuman animal behavior, it is necessary to have at least an approximate understanding of the theoretical role these terms are expected to play and how they might systematically be applied. Ethology is the study of animal behavior within the context of evolutionary theory. In particular, an animal's behavior is examined in light of its function and its evolution (see Hinde 1982 for a full explanation of the nature of ethology). Questions about the function of a particular behavior are commonly answered by explaining how the behavior in question contributes to the fitness of the organism. Mentalistic terms provide a level of description that is appropriate to the functional level of description that is the concern of evolutionary hypotheses. Mental states relate organisms to their environments through the notion of content. A mental state will be adaptive insofar as its content provides for appropriate links between environment and behavior. Mentalistic terms thus provide a natural vocabulary for cognitive ethologists to frame their hypotheses.

In the next section, we consider the concept of concept and its role in ethological explanations of nonhuman animal behavior. Moreover, we discuss whether the concept of concept can be used to describe some of the mental representations that explain animal behavior. Our intent is not to provide an extensive philosophical treatment of the concept of concept. In particular, we cannot hope to consider all the constraints on concept ascription that have been discussed in the recent philosophical literature. Among such topics are the alleged holism of belief and concept attribution (Quine 1960), the role of the environment in fixing belief (Putnam 1975, and Burge 1979) and the role of discrimination under ideal conditions in concept individuation (see Rey 1983 for discussion of this last issue and the various theoretical roles played by the concept of concept). Rather, we are concerned with elucidating a minimal constraint on cognitive representations for them to count as concepts. This analysis will enable us to suggest how one might search for empirical data to support the attribution of concepts to nonhuman animals.

2. Concepts of Concept. The "concept of "concept" has the ring of a philesophical topic, rather like the "meaning of 'meaning"". This latter 
topic has been extensively discussed by philosophers (e.g., Grice 1957, and Putnam 1975) and has led to specific methodological suggestions for cognitive ethologists. For instance, Dennett has made use of Grice's notion of levels of intentionality to suggest research strategies for cognitive ethologists (Dennett 1983). A recently published volume of papers arising from an interdisciplinary conference has also explored the possibilities of a fruitful interaction between philosophers and biologists on the topic of the meaning of primate signals (Harré and Reynolds 1984). In contrast, philosophical work on the concept of concept has been of little use to ethologists.

Many researchers in cognitive science regard the notion of internal representation to be a unifying theme in the different disciplines that make up cognitive science. Cooper, a psychologist, describes the task of the cognitive sciences as determining "the content, structure, and organization of knowledge" $(1982,145)$ which she equates with "the internal representations of the external world" (ibid.). The notion of an internal representation seems closely related to the notion of abstract idea found in Locke and Hume. Abstract ideas were the means by which human beings were supposed to be able to think about the individuals of some class without having to think about a particular individual. Thus the abstract idea of a horse included just those properties common to horses. Berkeley was famous for his attack on Locke's theory of abstract ideas, claiming that it was not possible to think of a horse without it having some particular color, height, and so on. One interpretation of Berkeley's objection suggests that it is based on the mistaken idea that the only way in which horses might be represented internally is in the form of a picture. The description of other possible forms of representation will go some way towards meeting Berkeley's objection, as well as going towards providing cognitive ethologists with a workable notion of concept. In addition, unlike a picture, an adequate representation for an abstract concept has a logical structure, or syntax, that connects its components (Fodor 1975). The search for representations with suitable structures is a primary goal for researchers in acquisition of concepts by computers (Schank et al. 1986).

The notion of concept is not identical with the notion of an internal representation since attributing internal representations in cases where one would not want to attribute a concept is possible. To develop this point, we will examine the research by Herrnstein et al. (1976) on pigeons. In their influential and widely cited paper, Herrnstein et al. have been taken to show that pigeons have concepts corresponding to certain natural categories (see, for example, Griffin 1981, and Dasser 1985). The three experiments conducted by Herrnstein et al. consisted of showing pigeons respectively pictures of trees, water, and a person. Included in these pictures were examples of each category that were considered "hard" by the 
experimenters. For instance, some pictures contained only parts of trees, or showed trees in the distance. In each case, the pictures falling into these categories were randomly mixed with pictures that showed nonexamples of the categories, including pictures that were considered near misses. Examples of near misses for trees include a picture of celery and a picture of a vine climbing a wall. The pigeons were capable of differentially pecking at a feeder key according to whether the pictures fell into the category or not. These results have been widely cited as demonstrating that pigeons have concepts.

The title of the paper by Herrnstein et al. is simply "Natural Concepts in Pigeons", but it is notable that the only other place in their paper where the word "concept" appears is in reference to human concept formation. "Concept" is never once defined, and it is replaced throughout by the potentially less innocuous, and philosophically less interesting, "category". The term "category" is less interesting since it is more easily interpreted to pertain to the human classificatory scheme rather than that of the pigeons. To say that the pigeons sort pictures into categories of tree or person is thus a considerably less specific claim about the internal representations involved than the claim that pigeons have concepts of those things. ${ }^{2}$

Herrnstein and his colleagues correctly make the point that no simple classification of the pictures in terms of common visual elements can be specified that will uniquely characterize those pictures that contain trees. Rather, they believe that the notion of "family resemblance" from Wittgenstein is more likely to describe what enables the classification of trees together. They suggest that pigeons have an innate disposition to infer a tree category from seeing instances of trees.

What seems to follow from these experiments is that pigeons are able to recognize specific properties in particular examples, and use these properties to recognize a general class or category. We are supposing that an explanation of this ability will attribute some kind of internal representation to guide the classification. But is this enough to allow us to say that the pigeons possess the corresponding concepts? ? $^{3}$ It is possible to teach a human being to sort distributors from other parts of car engines

\footnotetext{
${ }^{2}$ One might criticize the paper by Herrnstein et al. as providing nothing more than an argument by suggestion for the claim that pigeons have concepts. Since, however, they never say that pigeons do have concepts, it might be argued that they were never claiming that they do. Instead, it could be claimed that they were investigating the ability of pigeons to recognize and discriminate objects that are distinguished in human conceptual schemes. Unfortunately, their research is widely cited for having shown concepts in pigeons, so even if that was not their intention, it has, nonetheless, been the consequence. Subsequent publications by Herrnstein reinforce the view that he meant concepts in pigeons to be equated with human concepts (e.g., Herrnstein 1984).
}

${ }^{3}$ This question has also occurred to some psychologists. See, for example, Lea (1984). 
based on a family resemblance between shapes of distributors. But this ability would not be enough for us to want to say that the person has the concept of a distributor. In a suitably constrained environment, such a person need not have a representation of any information other than the shape to accomplish the sorting. ${ }^{4}$

It is beyond the scope of this paper to provide a theory of concept individuation. Our aim instead is to provide means of assessing the similarity between human mental processes and those of animals. Humans may represent environmental features in different ways and the question arises whether animals do likewise. In order to explain the different forms of representation, it will be useful to introduce a distinction between different ways of using the notion of recognition. The distinction to be made is between recognizing an $X$, and recognizing something as an $X$ or recognizing it to be an $\mathbf{X} .^{5}$ The first of these can be thought of as an extensional characterization of a discriminatory ability. The organism said to have the ability has some way of sorting things into the classes specified $(X$ and not- $X$ ), but this may be achieved by way of properties that are accidentally coextensive (see discussion below). The second says something about the organism's system of internal representation. To have a concept of $X$ where the specification of $X$ is not exhausted by a perceptual characterization, it is not enough just to have the ability to discriminate $X$ 's from non- $X$ 's. One must have a representation of $X$ that abstracts away from the perceptual features that enable one to identify $X$ 's. In the case of distributors, for example, once a person knows what distributors do, they have a representation that takes them away from mere shape recognition. We are not trying here to give an account of either necessary or sufficient conditions for the attribution of the concept of a distributor to someone. Rather, we are pointing out that some forms of representation of distributors allow for more sophisticated behavior with respect to distributors. For instance, having knowledge of the function of distributors will help subjects to categorize anything that plays that role even if its shape radically diverges from the pattern they originally based their discriminations upon. It might also allow them to reject some distributor-shaped non-distributors.

We are not denying the possibility that pigeons have concepts. However, the experiments conducted by Herrnstein et al. do not warrant the

\footnotetext{
${ }^{4}$ In case one thinks that the real reason for saying human subjects do not have the concept of distributor is that they would incorrectly sort a distributor-shaped non-distributor, consider that the pigeons were not tested on pictures of accurate models of trees either. Allen (1989) argues elsewhere that the possibility of classification errors of objects outside the normal range of experience does not impugn attributions of intentional states to humans or animals.

${ }^{5}$ This distinction is often ignored in the practice of ordinary speech. We are not making any claim that ordinary speech is incorrect, or that its practice should be changed.
} 
conclusion that pigeons have abstract concepts such as those of tree or person. The limitations of the Herrnstein approach have recently been discussed by D'Amato and van Sant (1988). They used slide presentations to cebus monkeys to determine whether monkeys have the concept of a person. The monkeys were trained in a manner similar to the pigeons in Herrnstein's experiments. While D'Amato and van Sant claim to have evidence for the representation of the person concept in cebus monkeys, they express reservations. In particular, they admit that their experiments do not successfully distinguish between stimulus generalization and conceptmediated behavior. They also state that "continued efforts along similar lines are not likely to prove fruitful" $(1988,54)$, citing uncertainty about the concept of concept as one of the reasons. In the next section, we hope to defuse this kind of pessimism.

In this paper, we will not concern ourselves with the attribution of concepts such as those of red or square. Such concepts, while they may involve abstraction from stimuli, are likely to be more perceptually direct than concepts like tree, person or distributor. We will deal with the structure of these higher level concepts. As an example of how theoretical considerations about concepts apply to empirical research, we turn our attention to behavior towards the concept of death. The next section discusses why death is a suitable topic and provides empirical observations that have been made of animal responses to death.

3. Behaviors in Response to Death. Animal response to death is a subject which has been of considerable interest to researchers in animal cognition (Griffin 1981). For some species, death of a group member represents a substantial loss. In the case of death of a mature animal, this constitutes a loss of group resources (e.g., defense against predators or competitors). When an infant dies, any further "caring" behavior shown by the parents represents a potential waste of that organism's resources. In many species, the presence of dead organisms poses a hazard thus making behavior which removes the dead individual adaptive. The ubiquity of death in animal experience, and the clear advantage for some individuals of some species of being able to recognize death and modify behavior accordingly, makes it of considerable interest to ethologists. In addition to the theoretical interest in death is a considerable body of empirical work describing the response of individuals to dead animals across a variety of taxa. This body of data makes death a suitable topic for crossspecies comparisons.

While scientific literature presents a fair amount of discussion of animal reactions to death, much of what is written is anecdotal in nature. Although we must be careful about the conclusions we draw from published reports, it is possible to distinguish some trends in the varying abilities 
of different species to recognize and react to death. In no species are reactions to death catalogued as thoroughly as they are in humans. However, in the examples discussed below, analogues to several of the human responses to death can be seen. We will describe some of the responses to death that have been reported in the animal literature before attempting to interpret the responses.

Some of the most thoroughly understood behavior in reaction to dead conspecifics occurs in ants, particularly Pogonomyrmex barbatus. Their behavior is described by E. O. Wilson (1971) as follows:

The transport of dead nestmates from the nest is nevertheless one of the most conspicuous and stereotyped patterns of behavior exhibited by ants. . . . When a corpse of a Pogonomyrmex barbatus worker is allowed to decompose in the open air for a day or more and is then placed in the nest or outside near the nest entrance, the first sister worker to encounter it ordinarily investigates it briefly by repeated antennal contact, then picks it up and carries it directly away towards the refuse piles. . . . It was soon established that bits of paper treated with acetone extracts of Pogonomyrmex corpses were treated just like intact corpses . . . the worker ants appear to recognize corpses on the basis of a limited array of chemical breakdown products. They are, moreover, very narrow-minded on the subject. Almost any object possessing an otherwise inoffensive odor is treated as a corpse when daubed with oleic acid. This classification extends to living nestmates. (Pp. 278-279)

Cowgill (1972) has described the reaction of potto monkeys kept in captivity to the death of a cagemate. Two mated pairs of pottos had been kept in a single cage. The death of the dominant male's mate was followed by a period where his rate of feeding and overall activity level decreased. After a few days, the dominant male also died. Following this second death, the remaining pair were watched for a few months. The remaining pair spent a considerable part of their time apparently "searching" for their cagemate. Additionally, the two remaining animals would leave a portion of their food untouched, even when the food supply was reduced.

Among primates in the wild, a number of researchers have recorded observations of mothers carrying their dead infants for considerable periods of time. Jeanne Altmann's (1980) description of yellow baboon mothers in Kenya provides a perfect description of the general phenomenon:

Mothers persist in the apparently automatic embracing of their infants even after infant death. They continue to carry the decomposing and 
increasingly dehydrated corpse, despite the fact that this usually means that they walk three-legged, setting the corpse down whenever they stop to feed and then retrieving it again. . . . After about three days ... mothers leave the corpse on the ground for gradually increasing periods of time while they forage at greater distances away, eventually either lose it or leave it, looking back at the corpse with repeated signs of conflict and ambivalence and sometimes giving alarm barks. (Pp. 129-130)

Among human cultures, reactions to death vary considerably. Differing cultural, religious and scientific beliefs affect the treatment of dead bodies and the concept of death held by individuals in the different cultures. Although these differences exist, there is much that is common. For instance, all human cultures have some method for disposal or treatment of dead bodies. While the methods vary, they all have the effect of isolating living individuals from contact with a decomposing corpse. Other human reactions to death include various types of formal and informal mourning. Again, while these are different between cultures, it seems that there is a universal need for some sort of mourning behavior in response to death of close associates. The strength of the mourning response may be great enough to interfere with other behaviors related to death. For instance, some parents may be unable or unwilling to make the arrangements for the burial of a dead child. Examples such as this raise questions about the relationship between concepts and beliefs. However, since we are interested only in establishing that a certain level of mental representation is involved, we can avoid questions about the precise specification of the content of the representations.

4. Interpretation of Animal Response to Death. In ethology, what counts as a useful interspecific comparison between two behaviors is determined by the role those behaviors play in the survival and evolution of the respective species. In the behaviors described in the previous section, there are a number of analogies to human responses to death. The ambivalent baboons are like the distraught parents who will not accept the fact of their child's death. Even the ants' behavior is comparable to the human insistence on removing a corpse from the normal living and working areas. Some such parallels have been drawn in the popular science media, but there may be a useful scientific reason for such comparisons.

From an ethological perspective, the ants' behavior may have the same explanation at one level as human burial practices. That is, removal of dead conspecifics from the living quarters is adaptive (e.g., for reasons of disease control). The general statement of the hypothesis might be that the ability to recognize dead conspecifics will evolve in any species where 
removal of the dead confers a selective advantage. However, the mechanisms underlying this recognition ability will vary between different species. The stereotypicality of the ants' behavior is not enough to make us say that the ants do not recognize dead nestmates. However, it seems unreasonable to say that the ants recognize that their nestmates are dead. The ants are using chemical cues that within the normal limits of their environment serve to correctly pick out dead nestmates. Extensionally, within this environment, the class of dead ants and the class of objects with oleic acid are the same. Thus it is reasonable to say that they are able to recognize dead ants. But, their behavior is mediated by nothing more than the perceptual stimulus provided by oleic acid. Therefore, it is not reasonable to assert that they recognize nestmates as dead, or that they have a concept of death.

Humans, and indeed other animals, may not just respond to stimuli features of their environment that happen to latch onto the right extensional class. In the case of ants, no indication of death is independent of the presence of oleic acid. In humans, however, a variety of perceptual inputs count as evidence for death. Even more important than this variety is the fact that humans are able to modify what kinds of evidence will prompt them towards the normal behaviors (e.g., disposal and mourning) directed towards dead bodies. Thus, for instance, the advent of cardiopulmonary resuscitation means that lack of a pulse is no longer to be taken to mean that the victim is dead, although, of course, it still counts as evidence. Also, like ants, humans may be duped into believing that someone is dead when they are not (e.g., by the effects of some drugs). But unlike ants, humans who have been duped in this way normally will modify what they take in the future to be evidence of death so as to be careful not to be fooled by appearances. Humans are capable of recognizing something as dead because they have an internal representation of death that is distinct from the perceptual information that is used as evidence for death. It is this separate representation that is capable of explaining the human ability to reason about death rather than merely respond to death in the environment. ${ }^{6}$

We would attribute an abstract concept to an organism if there is evidence supporting the presence of a mental representation that is independent of solely perceptual information. In the following sections, we discuss two experiments that might provide such evidence.

5. Experiments. We have thus far developed an analysis of the notion of a nonperceptual concept that involves representation of some feature independently of its perceptual components. This analysis has not been

${ }^{6}$ Thanks to L. Hauser for clarification on this point. 
developed with full philosophical sophistication. It is, however, sufficient for us to suggest the kinds of experiments that enable one to determine to what extent the mental processing of nonhuman organisms reacting to death is similar to human mental processing. ${ }^{7}$ In our view, the experiments we present below do not enable us to make claims about the precise specification of the content of animal concepts. Instead, what we try to do is make plausible the claim that animals can be shown to be operating with internal representations that function rather like human concepts.

With this objective in mind, we can suggest two testable features of behavior. First, an organism whose internal representations are conceptlike should be able to generalize information obtained from a variety of perceptual inputs and use that information in a range of behavioral situations. For example, suppose animal $A$ recognizes animal $B$ as dead. Subsequently, $A$ is presented with a stimulus that would ordinarily have evoked a response towards $B$ were it alive. If $A$ is operating with a concept of death, it should be able to use the perceptual input that informed it of $B$ 's death to modify its response with respect to the subsequent stimulus. ${ }^{8}$ Observation of this kind of behavioral modification would make talk of concepts plausible. Our first experiment investigates the possibility of attaining the appropriate behavioral evidence. Secondly, organisms that can be said to possess a concept should be able to alter what they take as evidence for an instance of that concept. For example, when first presented with evidence that something is dead but then presented with conflicting evidence that it is alive, an animal should alter its responses to the first kind of evidence. Our second experiment is designed to address this feature.

Ethologists have traditionally preferred experiments that are "natural" over laboratory situations. The reasons for this are varied, but most can be related to the ethologists' attempt to provide evolutionary explanations of behavior. It is argued that these explanations are most valid when observations of animals are gathered in their natural habitats (i.e., those habitats in which natural selection has shaped their behavior, physiology, morphology, and so on). Thus, the experiments we describe are designed for a natural setting, although it would be possible to perform similar experiments in captivity.

The subjects for the first of our hypothetical experiments are East Af-

\footnotetext{
${ }^{7}$ These experiments, though focusing on the concept of death, should be useful for thinking about concepts in general.

${ }^{8} \mathrm{Here}$, the relation between concepts and beliefs might appear to raise its ugly head. Behavioral evidence notoriously appears to be unable to provide grounds for distinguishing between on the one hand believing $X$ falls under concept $C$, and behavior $B$ is appropriate to $C$ 's, and on the other hand believing $X$ is $D$, but $B$ is appropriate to $D$ 's. But while this might present a problem for determining whether the subject has concept $C$ or $D$, it need not present a problem for deciding whether or not the subject has any concepts at all.
} 
rican vervet monkeys. Vervets are appropriate subjects for such an experiment because a great deal of work has been done to address the possibility that their behavior is guided by complex mental abilities (Cheney and Seyfarth 1985, Hauser 1988). The experiment involves an analysis of how female vervet monkeys respond to the death of their own infants. It is well established that female vervets are capable of recognizing the individual distress calls of their infants and that other females in a group will look towards the mother of an infant that has just uttered such a call. These responses indicate knowledge of mother-infant pairings (Cheney and Seyfarth 1980). Adult males also appear to recognize the calls of their potential offspring (Hauser 1986). In cases where infants have recently died, these facts can be exploited by playing one of their previously recorded distress calls from a concealed speaker (see Cheney and Seyfarth 1980 for description of concealed playback experimental method; in such experiments, the response of vervets to the recorded calls is no different from their response to naturally occurring calls).

Vervet mothers might respond in three ways when presented with distress calls from their dead offspring:

(1) They might respond as they do while the infant is alive (i.e., look towards speaker).

(2) They might respond in a more agitated fashion (e.g., initiation of searching behavior).

(3) They might not respond at all, continuing the activity in which they were engaged prior to the playback.

For (1), it seems correct to say that this would not provide any evidence of a concept associated with death unless gradations in response are too subtle to be distinguished by visual observation. (This, of course, is not the same as saying that it provides evidence that they do not have a concept.) However, (2) and (3) present more interesting possibilities. For (2), two possible explanations suggest themselves. Either the mothers have taken the distress call as evidence that the infant is nearby, or the call has elicited some kind of "surprise" reaction. Whether or not the mother had seen the infant die is relevant here. If the mother saw her infant carried away by a predator, or saw it die due to disease, then the first explanation would seem likely only if the infant was not recognized as dead. ${ }^{9}$ The second explanation would be more likely for animals that had recognized the infants as dead. Control experiments that could distinguish

\footnotetext{
${ }^{9}$ Again, one might worry about being unable to rule out other interpretations. Perhaps the mother does recognize the infant as dead, but has other beliefs that interact so as to produce the observed behavior. In humans, certain beliefs in the existence of spirits might account for such behavior. But such an interpretation would require supporting evidence for those beliefs that is unlikely to be forthcoming in the case of the vervets.
} 
between the two explanations would help in the determination of whether the animals are operating with a concept. Reactions to distress calls by females other than the mother could help provide such a control. Vervets are vulnerable to predation by leopards (Struhsaker 1967, and Seyfarth et al. 1980), so it would be reasonable for a mother who saw her infant carried away in the jaws of a leopard to infer that it was dead even if this could not be precisely determined. One could compare the response of a mother who saw the infant carried away by a leopard to the response of a second female who did not. The only evidence available to the second female is that the infant is no longer present with the group. The cause of this is unknown to her. In such a situation one might expect the mother to be startled upon hearing the infant's call. On the other hand, one would not necessarily expect the second female to show the same response.

It is important to realize that, so far, the experimental outcomes described would not enable the experimenters to distinguish between animals that have a concept related to our concept of death versus some other concept such as that of being missing. Possibility (3), however, is more decisive in this regard. The ability to "turn off" a response seems to indicate that the animal has recognized the finality of the disappearance of the infant. ${ }^{10}$ If the infant were just believed to be missing, then the most adaptive response would be to begin searching when the distress call was heard. For vervet monkeys, since young infants are rarely separated from other group members for more than one to two hours, it seems unlikely that a failure to respond after a period of several days indicates a belief that the infant is missing. This "turning off" response could provide the basis for an adaptive explanation of conceptual representation of death. The ability to use an independent representation of death (a concept of death) to guide behavior would be advantageous if it allowed rapid modification of behavior in a wide variety of situations. For instance, if energy would be wasted by fruitless searching, then recognition of death will be advantageous if it deters such searching behavior. In the case of the ants described above, the direct link between perceptual input and behavior, without the intermediate step of conceptualization, leads to the "inappropriate" removal of live ants treated with oleic acid. In the ants' normal environment, dissociation of oleic acid from death is not needed. It might be wondered where the adaptive benefit from having a concept lies. Any mechanism that turned off the vervets' response would do. The answer to this question is not simple, but

\footnotetext{
${ }^{10} \mathrm{We}$ are assuming that the response to the distress call has been modified too quickly to make a behavioristic explanation, in terms of deconditioning, plausible. We have some indication (Hauser, unpublished data) that such quick changes in responsiveness do indeed occur in vervets.
} 
we would argue that adaptiveness of the general ability to form concepts arises from a history of variability in the vervets' environment that is not matched in the ants' (Allen 1989).

While thinking of a number of important controls that one would like to conduct for this experiment is possible, the majority turn out to be unacceptable, primarily for ethical reasons. One obvious control would involve removing infants from the group by direct intervention and then observing the mother's response to distress calls over a variety of conditions and period of time. However, the practical and ethical difficulties associated with such a procedure are often enormous, particularly with wild primate populations. ${ }^{11}$ Some of these difficulties might be alleviated in captive populations. The responses of captive animals are, however, often difficult to interpret and may be unreliable as guides to the responses of animals in their natural environment. Captive animals are often removed from their living groups for short periods of time (e.g., for medical testing); thus, most captive populations are accustomed to frequent removal and return of individuals from the group. In contrast, free-ranging vervets are rarely out of visual or auditory contact for extended periods of time. This means that disappearance can either be interpreted as death or as migration into another group. Although males leave their natal groups upon reaching reproductive maturity and transfer into neighboring groups, infants never do so (Cheney and Seyfarth 1983).

It is worth noting that the most interesting response (3) was, in fact, a lack of response to the call on the part of the vervets. The interpretation of a lack of behavior is tricky since there are a number of alternative explanations. For instance, the animal might not have heard the playback or it might have been so engrossed in what it was doing that it failed to notice the distress call. While it is possible to reasonably discount some of these possibilities, the experimenter is always faced with the possibility of some unconsidered factor interfering between the playing of the call and the production of a response on the part of the targeted individual. In addition to the problem of interference, a lack of response presents a further problem of interpretation. A definite behavioral response (e.g., searching) leads reasonably directly to an interpretation (e.g., that the infant is believed to be nearby). The interpretation is aided by the apparent purposiveness of the behavior. In contrast, no response could be interpreted in a number of ways; for example: the mother hears the call but does not believe it is her infant's, the mother hears the call but infers that she must have heard another infant since her own is dead, she thinks she hears the call but infers that she must not have heard anything since

\footnotetext{
${ }^{11}$ Such removal experiments are more common in studies of small mammals (e.g., rodents), birds and insects.
} 
the infant is dead. Undoubtedly, some of these interpretations are overly anthropomorphic. However, the general point is that the scant behavioral evidence itself does not distinguish between them.

Another disadvantage of the current experiment is its lack of general applicability to other animal species. Since the experiment relies on the ability of females to recognize the calls of their young, duplicating the experiment on other species would not always be possible. ${ }^{12}$ The second experiment we consider is constructed with this problem in mind, and has the benefit of being applicable to a wide range of species, including humans.

The second experiment attempts to investigate whether animals have the ability to alter what they take as evidence for death. To do this, we take an individual of any species and administer a drug that causes unconsciousness and depression of vital signs. As we remarked above, a human is unlikely to be fooled twice into thinking that someone administered this drug was in fact dead. In the first trial of our experiment, animals are placed in a situation where they are expected to react as if the drugged animal were dead. As the effects of the drug wear off, the animal revives and we record the behavior of the other individuals. For the second trial, the experiment is repeated some time later with the original animal being drugged and the other animals watched to see whether they react in the same way. The final trial of our experiment involves the same drug procedure, but a different individual as the target for the drug. The question here is whether a change or modification in response is generalized to any individual.

As with the first experiment, there are a number of possible responses and alternative interpretations of those responses. If the animals fail to modify their behavior between trials, this would tend to indicate that they make no distinction between death and its perceptual signs. On this basis, describing the behavior as concept-mediated would be unreasonable. If the animals modify their response both when the original animal is drugged again, and when the drug is administered to a new individual, this would seem to provide the strongest evidence that the animals are operating with a concept. A suitable control for this would be to see whether the animals continued to produce their normal responses to death in cases where they had additional evidence that the animal was dead (e.g., they saw the animal get killed). A third possibility is that the animals modify their response only in the case where the original animal was redrugged, but did not transfer this to cases where other animals were drugged. Although this case is perhaps less likely, it would present some interesting difficulties for interpretation. One possible interpretation is that the animals

\footnotetext{
${ }^{12}$ Note, however, that in several species, females recognize the calls of their young.
} 
have a concept of death, but that they believe that the first animal is faking being dead. Alternatively, one might interpret the results as showing that the animals do not have a concept of death since they do not generalize its conditions to all conspecifics.

This possibility raises a potential worry about concepts of death. Humans are capable of applying their concept to a wide variety of species, both plant and animal. But what if we discover that some animals only react to death in a more limited range of species (e.g., vervet monkeys recognize death in other monkeys and apes, but not in birds)? One might argue that this shows that individuals of this species do not have the concept of death. After all, it might be claimed, if a monkey cannot recognize that a tree is dead, then it does not know what dead means. Alternatively, one might argue that the animals do have the concept of death, but do not recognize that or do not care whether certain objects are capable of falling into its extension.

One view of concepts that is popular among philosophers (Quine 1960) and computer scientists (Quillian 1968) is that concepts are part of a network and that individual concepts can only be understood in the context of the network in which they are embedded. If such a view is correct, the animals' concepts will match the human concepts to the extent to which they are embedded in similar conceptual schemes. ${ }^{13}$ However, whether or not one thinks that a particular species of animal has some human concept of death, experiments such as those we have suggested, which would show whether animals have representations of information that are sufficiently dissociated from perceptual stimuli to count as concepts, may still lead one to claim that the species have some other, perhaps related, concepts.

Our second experiment is applicable to a broad range of species because it does not rely on communicative abilities or other organism-specific qualities. Nonetheless, in common with the preceding experiment, it is not without its own practical and ethical difficulties. This is made vivid by the suggestion of conducting the experiment on young human children, which would obviously be unacceptable. Nonetheless, it provides a uniform base for comparison across those species where such experiments are considered acceptable.

6. Summary. In this paper, we have attempted to describe a particular class of internal representations that we believe can be investigated in animals and humans alike, without danger of overanthropomorphizing. In many respects, the problems facing the animal researcher are similar

\footnotetext{
${ }^{13}$ Contrary to Quine, we believe that the discovery of these conceptual schemes is a matter for empirical research.
} 
to those facing psychologists studying prelinguistic children. It is possible to see how the experiments we have suggested could have analogues for investigation of human children. The problems are also relevant to philosophers interested in the interpretation of terms like "Gavagai" by radical translators (Quine 1960).

The notion of concept we have suggested is of particular use to ethologists. It fits well into functional explanations of flexibility in animal behavior. Concepts are capable of explaining complex abilities to generalize over variable stimuli, to rapidly produce appropriate responses to the common features underlying those stimuli, and to modify behavior when it is discovered that perceptual stimuli are unreliable guides to underlying features. Furthermore, this notion of a concept can be tested by suitably ingenious experimental design. We have attempted to describe two possible experiments. Our discussion of these experiments illustrates the difficulties associated with conducting this kind of research. However, many of the difficulties are practical or ethical rather than theoretical.

\section{REFERENCES}

Allen, C. (1989), "Attributing Intentional States to Animals: Philosophical Issues Arising in Cognitive Ethology”. Ph.D. Dissertation, University of California, Los Angeles.

Altmann, J. (1980), Baboon Mothers and Infants. Cambridge, MA: Harvard University Press.

Asquith, P. J. (1984), "The Inevitability and Utility of Anthropomorphism in Description of Primate Behaviour", in R. Harré and V. Reynolds (eds.), The Meaning of Primate Signals. Cambridge: Cambridge University Press; Paris: Editions de la Maison des Sciences de l'Homme, pp. 138-174.

Bachmann, C. and Kummer, H. (1980), "Male Assessment of Female Choice in Hamadryas Baboons", Behavioral Ecology and Sociobiology 6: 315-321.

Burge, T. (1979), "Individualism and the Mental", in P. French, T. Uehling and H. Wettstein (eds.), Midwest Studies in Philosophy. Vol. 4, Studies in Metaphysics. Minneapolis: University of Minnesota Press, pp. 73-121.

Burghardt, G. (1985), “Animal Awareness: Current Perceptions and Historical Perspective", American Psychologist 40: 905-919.

Cheney, D. L. and Seyfarth, R. M. (1980), "Vocal Recognition in Free-ranging Vervet Monkeys", Animal Behaviour 28: 362-367.

(1983), "Nonrandom Dispersal in Free-ranging Vervet Monkeys: Social and Genetic Consequences", American Naturalist 122: 392-412.

$\rightarrow$ - (1985), "Social and Non-social Knowledge in Vervet Monkeys", Philosophical Transactions Royal Society London B 308: 187-201.

Cooper, L. A. (1982), "Internal Representation", in D. R. Griffin (ed.), Animal Mind, Human Mind: Report of the Dahlem Workshop on Animal Mind-Human Mind. Berlin: Springer-Verlag, pp. 145-158.

Cowgill, U. M. (1972), "Death in Perodicticus", Primates 13: 251-256.

D'Amato, M. R. and van Sant, P. (1988), "The Person Concept in Monkeys (Cebus apella)", Journal of Experimental Psychology: Animal Behavior Processes 14: 43-55.

Dasser, V. (1985), "Cognitive Complexity in Primate Social Relationships", in R. A. Hinde, A. Perret-Clermont and J. Stevenson-Hinde (eds.), Social Relationships and Cognitive Development. Oxford: Clarendon Press, pp. 9-22.

Dennett, D. C. (1969), Content and Consciousness. London: Routledge \& Kegan Paul. 
(1983), "Intentional Systems in Cognitive Ethology: The 'Panglossian Paradigm' Defended", The Behavioral and Brain Sciences 6: 343-390.

Fodor, J. A. (1975), The Language of Thought. New York: Crowell.

(1981), Representations: Philosophical Essays on the Foundations of Cognitive Science. Cambridge, MA: MIT Press.

Gould, J. L. and Gould, C. G. (1982), “The Insect Mind: Physics or Metaphysics?", in D. R. Griffin (ed.), Animal Mind, Human Mind: Report of the Dahlem Workshop on Animal Mind-Human Mind. Berlin: Springer-Verlag, pp. 269-298.

Grice, H. P. (1957), "Meaning”, Philosophical Review 66: 377-388.

Griffin, D. R. (1981), The Question of Animal Awareness: Evolutionary Continuity of Mental Experience. Revised and Enlarged Edition. New York: Rockefeller University Press.

. (ed.) (1982), Animal Mind, Human Mind: Report of the Dahlem Workshop on Animal Mind-Human Mind. Berlin: Springer-Verlag.

Harnad, S. (ed.) (1987), Categorical Perception: The Groundwork of Cognition. Cambridge: Cambridge University Press.

Harré, R. and Reynolds, V. (eds.) (1984), The Meaning of Primate Signals. Cambridge: Cambridge University Press; Paris: Editions de la Maison des Sciences de l'Homme.

Hauser, M. D. (1986), "Male Responsiveness to Infant Distress Calls in Free-ranging Vervet Monkeys", Behavioral Ecology and Sociobiology 19: 65-71.

- (1988), "Invention and Social Transmission: New Data From Wild Vervet Monkeys", in R. Byrne and A. Whiten (eds.), Machiavellian Intelligence: Social Expertise and the Evolution of Intellect in Monkeys, Apes, and Humans. Oxford: Clarendon Press, pp. 327-343.

Herrnstein, R. J. (1984), "Objects, Categories, and Discriminative Stimuli", in H. L. Roitblat, T. G. Bever and H. S. Terrace (eds.), Animal Cognition: Proceedings of the Harry Frank Guggenheim Conference, June 2-4, 1982. Hillsdale, NJ: Lawrence Erlbaum Associates, pp. 233-261.

Herrnstein, R. J.; Loveland, D. H.; and Cable, C. (1976), "Natural Concepts in Pigeons", Journal of Experimental Psychology, Animal Behavior Processes 2: 285-302.

Hinde, R. A. (1982), Ethology: Its Nature and Relations with Other Sciences. New York: Oxford University Press.

Krebs, J. R. and Davies, N. B. (1984), Behavioral Ecology: An Evolutionary Approach. 2d ed. Sunderland: Sinauer Press.

Kummer, H. (1982), "Social Knowledge in Free-ranging Primates", in D. R. Griffin (ed.), Animal Mind, Human Mind: Report of the Dahlem Workshop on Animal Mind-Human Mind. Berlin: Springer-Verlag, pp. 113-130.

Lea, S. E. G. (1984), "In What Sense Do Pigeons Learn Concepts?", in H. L. Roitblat, T. G. Bever and H. S. Terrace (eds.), Animal Cognition: Proceedings of the Harry Frank Guggenheim Conference, June 2-4, 1982. Hillsdale, NJ: Lawrence Erlbaum Associates, pp. 263-276.

Munn, C. A. (1986), "The Deceptive Use of Alarm Calls by Sentinel Species in MixedSpecies Flocks of Neotropical Birds", in R. W. Mitchell and N. S. Thompson (eds.), Deception: Perspectives on Human and Nonhuman Deceit. Albany: State University of New York Press, pp. 169-175.

Premack, D. (1986), Gavagai! or The Future History of the Animal Language Controversy. Cambridge, MA: MIT Press.

Putnam, H. (1975), "The Meaning of 'Meaning'", in K. Gunderson (ed.), Minnesota Studies in the Philosophy of Science. Vol. 7, Language, Mind, and Knowledge. Minneapolis: University of Minnesota Press, pp. 131-193.

Quillian, M. R. (1968), "Semantic Memory", in M. Minsky (ed.), Semantic Information Processing. Cambridge, MA: MIT Press, pp. 227-270.

Quine, W. V. (1960), Word and Object. Cambridge: Technology Press of MIT.

Rey, G. (1983), "Concepts and Stereotypes", Cognition 15: 237-262.

Schank, R. C.; Collins, G. C.; and Hunter, L. E. (1986), "Transcending Inductive Category Formation in Learning", Behavioral and Brain Sciences 9: 639-686.

Seyfarth, R. M.; Cheney, D. L.; and Marler, P. (1980), "Monkey Responses to Three 
Different Alarm Calls: Evidence of Predator Classification and Semantic Communication", Science 210: 801-803.

Struhsaker, T. T. (1967), "Auditory Communication Among Vervet Monkeys (Cercopithecus aethiops)", in S. A. Altmann (ed.), Social Communication Among Primates. Chicago: University of Chicago Press, pp. 281-324.

Wilson, E. O. (1971), The Insect Societies. Cambridge, MA: Belknap Press of Harvard University Press. 